\title{
Prevalence of Plasmodium vivax VK210 and VK247 subtype in Myanmar
}

\author{
Tong-Soo Kim ${ }^{1,2 \dagger}$, Hyung-Hwan Kim ${ }^{3,7 \dagger}$, Sun-Sim Lee ${ }^{2 \dagger}$, Byoung-Kuk Na ${ }^{4}$, Khin Lin ${ }^{5}$, Shin-Hyeong Cho ${ }^{2}$, \\ Yoon-Joong Kang ${ }^{6,7}$, Do-Kyung Kim ${ }^{6,7}$, Youngjoo Sohn ${ }^{8}$, Hyuck Kim ${ }^{7}$, Hyeong-Woo Lee ${ }^{2,9^{*}}$
}

\begin{abstract}
Background: Plasmodium vivax is divided into two subtypes, a dominant form, VK210 and a variant form, VK247. This division is dependent on the amino acid composition of the circumsporozoite (CS) protein. In this study, the prevalence of the VK247 variant form of $P$. vivax was investigated in Myanmar.
\end{abstract}

Methods: The existence of malaria parasites in blood samples was determined by microscopic examination, polymerase chain reaction (PCR) and DNA hybridization assays. To test for antibodies against $P$. vivax and Plasmodium falciparum in blood samples, an indirect immunofluorescence antibody test (IFAT) was performed using asexual blood antigens. An enzyme-linked immunosorbent assay with synthetic VK210 and VK247 antigens was carried out to discriminate between the P. vivax subtypes.

Results: By thick smear examination, $73(n=100)$ patients were single infected with $P$. vivax, one with $P$. falciparum and 13 with both species. By thin smear, 53 patients were single infected with $P$. vivax, eight with only $P$. falciparum and 16 with both. Most of the collected blood samples were shown to be $P$. vivax positive $(n=95)$ by PCR. All cases that were positive for $P$. falciparum by PCR $(n=43)$ were also positive for $P$. vivax. However, 52 cases were single infected with $P$. vivax. IFAT showed antibody titres from 1:32 to 1:4,096. Additionally, using specific antibodies for VK210 and VK247, ELISA showed that 12 patients had antibodies for only the VK210 subtype, 4 patients had only VK247 subtype antibodies and 21 patients had antibodies for both subtypes. Using a DNA hybridization test, 47 patients were infected with the VK210 type, one patient was infected with VK247 and 23 patients were infected with both subtypes.

Conclusions: The proportion of the VK247 subtype in Myanmar was 43.1\% ( $n=25)$ among 58 positive cases by serodiagnosis and 25.6\% ( $n=24)$ among 94 positive cases by genetic diagnosis. In both diagnostic methods, the infection status of malaria patients is highly diverse with respect to malaria species, and multiple clonal infections are prevalent in Myanmar. Therefore, the complexity of the infection should be considered carefully when diagnosing malaria in Myanmar.

\section{Background}

Plasmodium vivax, a causative agent of relapsing benign tertian malaria, is the second most important malariacausing species and afflicts several hundred million people annually [1]. Malaria constitutes a major health problem and is deeply associated with socioeconomic burden in many temperate and most tropical countries. In Myanmar, malaria is ranked as the number one public health problem, and nearly 600,000 malaria patients

\footnotetext{
* Correspondence: rainlee67@yahoo.co.kr

† Contributed equally

${ }^{2}$ Division of Malaria and Parasitic diseases, Korea Centers for Disease Control and Prevention, Seoul 122-701, Republic of Korea
}

seek medical attention at health institutions annually. Among malaria species in Myanmar, Plasmodium falciparum accounts for $80 \%$ of infections, $P$. vivax accounts for $17.8 \%$ of infections and the remaining are due to Plasmodium malariae with mixed infections [2].

The surface membrane of all plasmodial sporozoites is covered by an antigen designated as circumsporozoite (CS) protein. The CS proteins have a central immunodominant region, consisting of tandemly repeated short amino acid sequences, which contain multiple copies of the immunodominant B cell epitope [3]. Because they are highly immunogenic and can induce a protective response in sporozoite-immunized experimental animals
C Biomed Central

(c) 2010 Kim et al; licensee BioMed Central Ltd. This is an Open Access article distributed under the terms of the Creative Commons Attribution License (http://creativecommons.org/licenses/by/2.0), which permits unrestricted use, distribution, and reproduction in any medium, provided the original work is properly cited. 
and in man, the CS proteins are being investigated as candidates for a human malaria vaccine. These immunodominant B cell epitopes within a large number of $P$. falciparum isolates of diverse geographical origin, and a smaller number of $P$. vivax isolates were examined and found to be conserved within the species [4]. A strain of $P$. vivax containing a variant repeat in its CS protein was first isolated in Thailand [5]. The CS repeat of this variant strain (Thai VK247) differs at 6/9 amino acids within the repeat sequence found in all previously described $P$. vivax CS protein. Following this discovery, several studies have been conducted to evaluate the global distribution of variant VK247; it was detected in indigenous populations of China [6], Brazil [7], Mexico $[8,9]$, Peru $[9,10]$, and Papua New Guinea [8].

It is known that the drug susceptibility of the VK247 subtype of $P$. vivax is slightly different than VK210 [11], as well as that Anopheles albimanus and Anopheles pseudopunctipennis differ in their susceptibilities to $P$. vivax circumsporozoite phenotypes. Anopheles albimanus is more susceptible to the VK210 subtype, whereas An. pseudopunctipennis is more susceptible to the VK247 subtype [12].

Here, the frequency of the two CSP variants (VK210 and VK247) in wild $P$. vivax isolates collected in Yangon and Mandalay, Myanmar was determined by ELISA and DNA hybridization. This effort may be useful for updating the anti-malarial control programme in Myanmar.

\section{Methods}

\section{Study areas and blood collection of clinical isolates of malaria}

Patients attending the Central VBDC (Vector Borne Diseases Control) clinic in Yangon and Wet-Won station hospital (Pyin Oo Lwin District) in Mandalay, Myanmar in January 2000 were selected for this study. All of the individuals exhibited clinical symptoms associated with malaria. Thin and thick blood smears were prepared from the blood collected for microscopic examination (magnification $7 \times 100$ ) from the fingertips of individuals. A local health unit employee read the Giemsastained thick blood smears in the fields, and treatment was administered to those individuals who tested positive for malaria, based on the guidelines of The Department of Health, the Union of Myanmar. And thin blood smears were examined by co-authors in laboratory condition. Before treatment, additional blood samples of approximately $3 \mathrm{ml}$ were collected from each individual whose infection was confirmed by microscopic examination $(n=100)$. The blood samples were transferred to the National Institute of Health, Korea Centers for Disease Control and Prevention, Korea, for further polymerase chain reaction (PCR), DNA hybridization genotyping, and antibody analysis. Informed consent was obtained from all patients. The study protocol was approved by the Department of Health (Upper Myanmar), the Union of Myanmar.

\section{Amplification of CS the protein gene}

For the purpose of preparing variant CS protein genes, genomic DNA was extracted from the whole blood of a malaria patient using the QIAamp Blood Kit (Qiagen Co., Hilden, Germany). PCRs were performed with the AccuPower PCR Premix (Bioneer Co., Taejeon, Korea), $50 \mathrm{ng}$ of purified genomic DNA, 40 pmoles each forward (F1; 5' -TCCCCACGCACTGCGGGCACAAT-3') and reverse primers (R1; 5'-TTAATATGCACCGTGAGGACGCC-3'), and the total volume was adjusted to 20 $\mu \mathrm{l}$ with distilled water. The F1 primer contained several nucleotides of the signal peptide and the first 4 amino acids of the mature protein. The $\mathrm{R} 1$ primer contained the region starting 21 bases downstream of the stop codon so that this primer set would amplify the entire mature CS protein gene. The cycling conditions were performed as follows: denatured at $94^{\circ} \mathrm{C}$ for $5 \mathrm{~min}$; 35 cycles of $1 \mathrm{~min}$ at $94^{\circ} \mathrm{C}, 1 \mathrm{~min}$ at $49^{\circ} \mathrm{C}, 2 \mathrm{~min}$ at $72^{\circ} \mathrm{C}$; and a final incubation at $72^{\circ} \mathrm{C}$ for $5 \mathrm{~min}$. A second PCR performed under the same conditions except that the PCR products $(2-5 \mu \mathrm{l})$ were added instead of genomic DNA and that different forward (F2; 5'-AAAAAGGATGGAAAGAAAG-3') and reverse (R2; 5' GACTTTTCATTTGGGGCA-3') primers were included in the reaction [13]. To exclude the blood samples that were co-infected with P. falciparum, PCRs were performed with a $P$. falciparum specific primer set that amplifies the ring-infected erythrocyte surface antigen (RESA), as described by Wooden et al [forward (5'GATCAAGGAGGAGAGAACC-3') and reverse (5'CAGCATTAACACCAACACC-3')] [14]. All the PCR products were analysed on a $1.2 \%$ agarose gel, confirmed under UV transillumination and purified with the NucleoSpin Extract kit (Macherey-Nagel, Duren, Germany). The purified PCR products were ligated with the pCR2.1 cloning vector (Invitrogen Co., Carlsbad, CA, USA) and then transformed into E. coli INV $\alpha$ F' according to the procedures of Invitrogen.

\section{Genotyping of PCR products by DNA hybridization}

Half of the $20 \mu \mathrm{l}$ PCR products was blotted onto a nylon membrane by a slot blotter. Two oligonucleotides, AL116 (5'-GGTGATAGAGCAGATGGA-3') for VK210 type and AL114 (5'-ATCAACCAGGAGCAAATG-3') for VK247 type, were used as probes in DNA hybridization [15]. These probes were end-labeled with ${ }^{35} \mathrm{~S}-\alpha-$ dATP using a 3 '-end labeling kit (Amersham Pharmacia Biotech, Uppsala, Sweden) for $1 \mathrm{hr}$ at $37^{\circ} \mathrm{C}$. The radiolabeled oligonucleotides were separated from unincorporated nucleotides on a Sephadex column (Amersham 
Pharmacia Biotech). Nylon membranes were soaked for $10 \mathrm{~min}$ in denaturation buffer and washed with distilled water, and then incubated with freshly prepared neutralization buffer two times for $15 \mathrm{~min}$. After incubating the nylon membranes in $5 \times \mathrm{SSC}(0.75 \mathrm{M}$ sodium chloride and $0.075 \mathrm{M}$ sodium citrate) for $5 \mathrm{~min}$, the membranes were pre-hybridized for $1 \mathrm{hr}$ at $42^{\circ} \mathrm{C}$ in $5 \times \mathrm{SSC}$, $1 \%$ SDS, $1 \times$ Denhart's solution (1\% BSA, 1\% Ficoll 400, and $1 \%$ polyvinyl pyrrolidone), and $5 \%$ sodium pyrophosphate. Hybridizations were performed in the same buffer with radiolabeled nucleotides for $12 \mathrm{hrs}$ at $42^{\circ} \mathrm{C}$. Each nylon membranes was co-reacted with anti-AL116 (5'-CCACTATCTCGTCTACCT-3') and anti-AL114 (5'TAGTTGGTCCTCGTTTAC-3') for positive controls. After hybridization, nylon membranes were washed three times for $5 \mathrm{~min}$ each at $42^{\circ} \mathrm{C}$ in $5 \times \mathrm{SSC}$ and $1 \%$ sodium pyrophosphate. These nylon membranes were air-dried and exposed to X-ray film (Kodak X-Omat, Sigma, St. Louis, MO, USA) with an intensification screen at $-80^{\circ} \mathrm{C}$ for $72 \mathrm{hrs}$.

\section{DNA sequencing and analysis}

After genotyping $P$. vivax, several candidates that could contain the variant CS protein gene were selected for DNA sequencing. After gel extraction with a Qiagen gel extraction kit, PCR products were ligated into the pCR2.1 cloning vector and transformed into Escherichia coli INV $\alpha$ F'. The PCR product inserted into E. coli was selected on ampicillin and 5-bromo-4-chloro-3-indolyl $\beta$-D-galactopyranoside (X-gal) containing medium. To determine whether the proper DNA was in E. coli, restriction enzyme digestion was done with EcoRI after plasmid isolation with a Qiagen plasmid isolation kit according to the method supplied by manufacture. The variant CS protein gene sequence was determined using the ABI PRISM dye terminator cycle sequencing ready reaction kit FS (Perkin Elmer, Cambridge, MA, USA) according to the supplied manual. M13 reverse and M13 forward (-20) primers were used in sequencing. Nucleotide and deduced amino acid sequences were analysed using EditSeq and Clustal in the Megalign program, and the multiple alignment programs in the DNASTAR package (DNASTAR, Madison, WI, USA). The internet-based BLAST search program of the National Center for Biotechnology Information (NCBI) was used to search protein databases.

\section{Indirect immunofluorescence antibody test}

To test for antibodies against malaria, an indirect immunofluorescence antibody test (IFAT) was performed with whole blood antigens for $P$. vivax and $P$. falciparum as described by Sulzer et al [16]. Briefly, $10 \mathrm{ml}$ of malaria parasite infected blood was collected by venopuncture from $P$. vivax and $P$. falciparum patients. After removing the plasma, the cells were suspended in phosphate buffered saline (PBS, $\mathrm{pH} 7.2$ ) and centrifuged for $5 \mathrm{~min}$ at 2,500 rpm. The supernatant was discarded the cells were suspended in fresh PBS and the wash step was repeated three more times. Finally, an appropriate amount of PBS was added to maintain the parasitaemia at no less than $1 \%$. The cells were dropped onto each well of Teflon coated slides. After drying them in room temperature for $12 \mathrm{hrs}$, the slides were kept at $-70^{\circ} \mathrm{C}$ until required. To determine the antibody titres of each patient against $P$. vivax and $P$. falciparum, the antigen slides were fixed in pre-cooled acetone $\left(-20^{\circ} \mathrm{C}\right)$ for 10 min, washed with PBS and added $20 \mu$ diluted sera from $1: 32$ to $1: 8,192$ ( $\mathrm{vol} / \mathrm{vol}$ ) was added to each well. The positive and negative controls were dropped on each slide and incubated in a moisture chamber for 30 $\min$ at $37^{\circ} \mathrm{C}$. The reactions were stopped by washing out the reacted sera with PBS. The slides were immerged in PBS for $6 \mathrm{~min}$ and then dried at room temperature. Diluted FITC conjugated anti-human IgG (Sigma, 1:32 vol/vol in PBS) was added to each well and incubated and washed using the same method described above. Then several drops of buffered glycerol were added to the samples and covered with coverslips. The slides were examined under a $40 \times$ fluorescence objective.

\section{Enzyme-linked immunosorbent assay}

To verify that the blood samples had antibodies against the synthetic VK210 and VK247 antigens obtained from R.A Wirtz (Centers for Disease Control and Prevention, Atlanta, GA, USA), an enzyme-linked immunosorbent assay was performed with these antigens. Briefly, $50 \mu \mathrm{l}$ of capture antigen solution $(1 \mu \mathrm{l}$ antigen/50 $\mu \mathrm{l})$ was placed in a 96-well plate (Corning, Lowell, MA, USA) and incubated for $12 \mathrm{hrs}$ at room temperature. The cells were aspirated and filled with blocking buffer (1\% BSA, $0.05 \%$ PBS-Tween 20) and incubated for $1 \mathrm{hr}$ at room temperature. After washing the wells with $0.05 \%$ PBSTween 20 three times, the human serum samples in blocking buffer at a dilution of 1:100 (vol/vol) were added to each of the wells. The four positive and four negative control serum samples were also added to each plate. After a 2-hr incubation at room temperature, the plates were washed with $0.05 \%$ PBS-Tween 20 three times and then the peroxidase conjugated anti-human IgG (Sigma, 1:2,000, vol/vol) diluted in blocking buffer was added and incubated again for $1 \mathrm{hr}$ at room temperature. The reaction was completed by washing the plates as described above. To develop the color, $100 \mu \mathrm{l}$ of 2.2'-azino-di-(3-ethyl-benzthiozoline-6-sulfonic acid) (ABTS) peroxidase substrate (Kirkegaard \& Perry Laboratories, Gaithersburg, MD, USA) was added and incubated for $30 \mathrm{~min}$. The absorbance of the mixture 
Table 4 Serological typing of $P$. vivax isolates with circumsporozoite (CS) protein.

\begin{tabular}{|c|c|c|c|c|}
\hline $\begin{array}{l}\text { VK210 } \\
\text { (Single) }\end{array}$ & $\begin{array}{l}\text { VK247 } \\
\text { (Single) }\end{array}$ & $\begin{array}{l}\text { VK210+VK2473 } \\
\text { (Double) }\end{array}$ & Negative & Total \\
\hline 12 & 4 & 21 & 42 & 100 \\
\hline \multicolumn{5}{|c|}{$\begin{array}{l}1 \text {; isolates that reacted with synthetic peptide carrying the amino acid } \\
\text { composition [GDRA(D/G)GQPA] of the dominant form of } P \text {. vivax. }\end{array}$} \\
\hline \multicolumn{5}{|c|}{$\begin{array}{l}{ }^{2} \text {; isolates that reacted with synthetic peptide carrying the amino acid } \\
\text { composition }[\mathrm{ANGA}(\mathrm{G} / \mathrm{D})(\mathrm{N} / \mathrm{D}) \mathrm{QPG}] \text { of the variant form of } P \text {. vivax. }\end{array}$} \\
\hline \multicolumn{5}{|c|}{${ }^{3} ;$ isolates that reacted with both types of $P$. vivax. } \\
\hline
\end{tabular}

five cases. Using this technique, any case was not infected only by $P$. falciparum: all were co-infected with $P$. vivax and P. falcipaum (Table 1). Additionally, positive rate in PCR was much higher than that of microscopic examination. Therefore, it is highly recommended that more intensive concentration is needed when examining the blood films in field and laboratory conditions. The fact that there were less P. falciparum cases than $P$. vivax cases is due to the season of blood sample collection, as $P$. vivax is predominant during the winter season in Myanmar [2].

During CS protein genotyping of $P$. vivax, one case was infected with only VK247, the variant form. Most of patients were infected with dominant form, VK210. Even though one case was infected with VK247 subtype only, a total of 23 cases $(24.5 \%)$ were co-infected with VK247 and VK210 (Table 2). A similar distribution pattern of VK210 and VK247 mixed infections was observed in Thailand (25.6\%) [20]. Although, all the cases of the variant form were not analysed, VK247 of Myanmar has high homology with the Thai strain (97.2\%, GenBank accession No. U08983), it has a different number of nonapeptide repeats (i.e., Thai strain has 18 times repeat of ANGA(G/D)(N/D)QPG but the Myanmar strain has 19 repeats of $\mathrm{AN}(\mathrm{G} / \mathrm{E}) \mathrm{A}(\mathrm{G} / \mathrm{D})(\mathrm{N} /$ D)QPG. This isolate has a different amino acid repeat in a third of the nonapeptide repeats, that is, usually the third amino acid is conserved as $\mathrm{G}$, which is translated from GGA or GGG, however, in some of the repeats, it has an $E$ instead of $G$, which is translated from GAG [5]. Interestingly, sporozoites carrying the VK247 sequence were more frequently produced in An. albimanus than sporozoites with the VK210 sequence [21]. Therefore, these results suggest that different vector species might be co-distributed in the study area and multiple infections by different $P$. vivax strains often occur in individuals throughout the study area, which is similar to the situation in Thailand [22].

Seroimmunological diagnosis, in particular by IFAT, is an important tool for the detection of malaria, especially when microscopic evidence of the parasites is not available due to the several reasons [23]. All patients had antibodies against whole blood antigens of $P$. vivax by IFAT. Among them, 94 cases (94\%) had relatively high antibody titres above $1: 256$. In patients who were infected by $P$. falciparum, seven cases did not have antibodies against whole blood antigens. These cases might have been infected by $P$. falciparum recently. Additionally, the 67 cases had antibody titres above 1:256. These results indicate that most patients had been exposed to both species (Table 3). The number of antibody positive cases against VK247 $(\mathrm{n}=25)$ antigen is similar to those determined by DNA hybridization $(\mathrm{n}=24)$. In ELISA, Twenty-one cases showed mixed infection by VK210 and VK247, and 33 cases were positive for VK210 antigen. This finding indicates that VK247 transmission has actively progressed in Myanmar. There are 36 Anopheline mosquitoes in Myanmar [24], and there are differences in the sporozoite production of VK210 and VK247 in each vector mosquitoes [21]. Therefore, intensive field studies should be done in Myanmar to elucidate the relationship between $P$. vivax subtypes and sporozoites production rates in each Anopheline mosquitoe for malaria control in Myanmar.

\section{Conclusions}

A major finding of this study was that the prevalence of malaria in Myanmar is complex like elsewhere; these data might be used as fundamental information for molecular epidemiological and seroepidemiological studies in Myanmar. The geographic location of Myanmar appears to contribute to the large diversity of $P$. vivax genotypes and serotypes in this country. Migration of people within the country and between the neighbouring countries may introduce a $P$. vivax population with different alleles, thereby resulting in the complexity of malaria parasites. Interallelic recombination between different parasite populations in the mosquito vector may also facilitate genetic variation of $P$. vivax. Further studies using a large number of blood samples collected from different geographic areas are required not only to determine the nationwide parasite heterogeneity and detailed malaria epidemiology in Myanmar but also to implement malarial control programmes in the country.

\section{Acknowledgements}

We are grateful to all blood donors. We thank Dr. Wirtz RA for donation of the ELISA kit for VK210 and VK247 serotyping. This work was supported by an internal grant from Korea National Institute of Health, Ministry of Health and Welfare, Republic of Korea.

\section{Author details}

'Department of Parasitology, College of Medicine, Inha University, Incheon 405-751, Republic of Korea. 'Division of Malaria and Parasitic diseases, Korea Centers for Disease Control and Prevention, Seoul 122-701, Republic of Korea. ${ }^{3}$ Vascular Medicine Research Unit, Brigham and Women's Hospital, Harvard Medical School, Cambridge, MA 02139, USA. ${ }^{4}$ Department of Parasitology and Institute of Health Sciences, Gyeongsang National University College of Medicine, Jinju 660-751, Republic of Korea. ${ }^{5}$ Department of Medical Research (Upper Myanmar), Pying Oo Lwin Township, Mandalay, Myanmar. ${ }^{6}$ Faculty of Biomedical Engineering, Jungwon 
University, Goesan 367-805, Republic of Korea. ${ }^{7}$ International Research Center of Bioscience and Biotechnology, Goesan 367-805, Republic of Korea. ${ }^{8}$ Department of Gynecology, College of Oriental Medicine, Sangji University, Wonju 220-717, Republic of Korea. ${ }^{9}$ Department of Pathology, University of Florida, J-566, 1600 SW Archer Road, Gainesville, FL 32610, USA.

\section{Authors' contributions}

TSK, HHK, and HWL conceived and designed the study and contributed to execution of research. TSK, HHK, and HWL wrote the manuscript. HWL, KL, BKN, YJK and DKK collected the blood samples in the field. YS, SSL, SHC and HK examined the thin blood films and KL thick blood film. YJK, DKK, YS and HK helped in the design and implementation of field studies. TSK, SSL, HHK and HWL carried out PCR, DNA hybridization, ELISA and IFAT. All authors have read and approved the final manuscript.

\section{Competing interests}

The authors declare that they have no competing interests.

Received: 28 May 2010 Accepted: 9 July 2010 Published: 9 July 2010

\section{References}

1. Mendis K, Sina BJ, Marchesini P, Carter R: The neglected burden of Plasmodium vivax malaria. Am J Trop Med Hyg 2001, 64:97-106.

2. Vector Borne Diseases Control Project-Department of Health: Annual Report Myanmar 1997.

3. Arnot DE, Barnwell JW, Tam JP, Nussenzweig V, Nussenzweig RS, Enea V: Circumsporozoite protein of Plasmodium vivax: gene cloning and characterization of the immunodominant epitope. Science 1985, 230:15-818.

4. Shi YP, Alpers MP, Povoa MM, Lal AA: Diversity in the immunodominant determinants of the circumsporozoite protein of Plasmodium falciparum parasites from malaria endemic regions of Papua New Guinea and Brazil. Am J Trop Med Hyg 1992, 47:844-851.

5. Rosenberg R, Wirtz RA, Lanar DE, Sattabongkot J, Hall T, Waters AP, Prasittisuk C: Circumsporozoite protein heterogeneity in the human malaria parasite Plasmodium vivax. Science 1989, 245:973-976.

6. Han GD, Zhang XJ, Zhang HH, Chen XX, Huang BC: Use of PCR/DNA probes to identify circumsporozoite genotype of Plasmodium vivax in China. Southeast Asian J Trop Med Pub Health 1999, 30:20-23.

7. Branquinho MS, Lagos CB, Rocha RM, Natal D, Barata JM, Cochrane AH, Nardin E, Nussenzweig RS, Kloetzel JK: Anophelines in the state of Acre, Brazil, infected with Plasmodium falciparum, $P$. vivax, the variant $P$. vivax VK247 and P malariae. Trans R Soc Trop Med Hyg 1993, 87:391-394.

8. Kain KC, Brown AE, Webster HK, Wirtz RA, Keystone JS, Rodriguez MH, Kinahan J, Rowland M, Lanar DE: Circumsporozoite genotyping of global isolates of Plasmodium vivax from dried blood specimens. J Clin Microbiol 1992, 30:1863-1866.

9. Kain KC, Wirtz RA, Fernandez I, Franke ED, Rodriguez MH, Lanar DE: Serologic and genetic characterization of Plasmodium vivax from whole blood-impregnated filter paper discs. Am J Trop Med Hyg 1992, 46:473-479.

10. Need JT, Wirtz RA, Franke ED, Fernandez R, Carbajal F, Falcon R, San Roman E: Plasmodium vivax VK247 and VK210 circumsporozoite proteins in Anopheles mosquitoes from Andoas, Peru. J Med Entomol 1993, 30:597-600.

11. Kain KC, Brown AE, Lanar DE, Ballou WR, Webster HK: Response of Plasmodium vivax variants to chloroquine as determinated by microscopy and quantitative polymerase chain reaction. Am J Trop Med Hyg 1993, 49:478-484.

12. González-Cerón L, Rodriguez MH, Nettel JA, Villarreal C, Kain KC, Hernández JE: Differential susceptibility of Anopheles albimanus and Anopheles pseudopunctipennis to infections with coindigenous Plasmodium vivax variants VK210 and VK247 in southern Mexico. Infect Immun 1999, 67:410-412.

13. Mann VH, Huang $T$, Cheng $Q$, Saul A: Sequence variation in the circumsporozoite protein gene of Plasmodium vivax appears to be regionally biased. Mol Biochem Parasitol 1994, 68:45-52.

14. Wooden J, Gould EE, Paul AT, Sibley CH: Plasmodium falciparum: a simple polymerase chain reaction method for differentiating strains. Exp Parasitol 1992, 75:207-212.
15. Qari SH, Collins WE, Lobel HO, Taylor F, Lal AA: A study of polymorphism in the circumsporozoite protein of human malaria parasites. Am J Trop Med Hyg 1994, 50:45-51.

16. Sulzer AJ, Wilson M, Hall EC: Indirect fluorescent-antibody tests for parasitic diseases. V. An evaluation of a thick-smear antigen in the IFA test for malaria antibodies. Am J Trop Med Hyg 1969, 18:199-205.

17. Suwanabun N, Sattabongkot J, Wirtz RA, Rosenberg R: The epidemiology of Plasmodium vivax circumsporozoite protein polymorphs in Thailand. Am J Trop Med Hyg 1994, 50:460-464.

18. Burkot TR, Wirtz RA, Paru R, Garner P, Alpers MP: The population dynamics in mosquitoes and humans of two Plasmodium vivax polymorphs distinguished by different circumsporozoite protein repeat regions. Am J Trop Med Hyg 1992, 47:778-786.

19. Rodriguez MH, González-Cerón L, Hernandez JE, Nettel JA, Villarreal C, Kain KC, Wirtz RA: Different prevalences of Plasmodium vivax phenotypes VK210 and VK247 associated with the distribution of Anopheles albimanus and Anopheles pseudopunctipennis in Mexico. Am J Trop Med Hyg 2000, 62:122-127.

20. Cui L, Mascorro CN, Fan Q, Rzomp KA, Khuntirat B, Zhou G, Chen H, Yan G, Sattabongkot J: Genetic diversity and multiple infections of Plasmodium vivax malaria in Western Thailand. Am J Trop Med Hyg 2003, 68:613-619.

21. Gonzalez JM, Hurtado S, Arevalo-Herrera M, Herrera S: Variant of the Plasmodium vivax circumsporozoite protein (VK210 and VK247) in Colombian isolates. Mem Inst Oswaldo Cruz, Rio de Janeiro 2001, 96:709-712.

22. Coleman RE, Sithiprasasna R, Kankaew P, Kiattibut C, Ratanawong S, Khuntirat B, Sattabongkot J: Naturally occurring mixed infection of Plasmodium vivax VK210 and P. vivax VK247 in Anopheles mosquitoes (Diptera: Culicidae) in western Thailand. J Med Entomol 2002, 39:556-559.

23. Gotoh M, Nagase S, Hirayama K, Ishizu T, Irrsuka T, Kobayasi M, Aoki Y, Aoyagi K, Koyama A, Irie Y, Kano S, Suzuki M: Plasmodium vivax malaria infection diagnosed by indirect fluorescent antibody test. Intern Med 1995, 34:32-35.

24. Ool $\Pi$, Storch $V$, Becker $N$ : Review of the anopheline mosquitoes of Myanmar. J Vector Ecol 2004, 29:21-40.

doi:10.1186/1475-2875-9-195

Cite this article as: Kim et al.: Prevalence of Plasmodium vivax VK210 and VK247 subtype in Myanmar. Malaria Journal 2010 9:195.

\section{Submit your next manuscript to BioMed Central and take full advantage of:}

- Convenient online submission

- Thorough peer review

- No space constraints or color figure charges

- Immediate publication on acceptance

- Inclusion in PubMed, CAS, Scopus and Google Scholar

- Research which is freely available for redistribution 